\title{
PENILAIAN KINERJA ORGANISASI MENGGUNAKAN METODE KEY PERFORMANCE INDICATORS (KPI) (STUDI KASUS: HIMPUNAN MAHASISWA TEKNIK INDUSTRI UNIVERSITAS WIDYATAMA)
}

\author{
Aliyah Mira Ky ${ }^{1}$, Gustian Adhitya Prayogi², Adi Sukmana ${ }^{3}$ \\ Fakultas Teknik $1,2,3$ \\ Universitas Widyatama \\ Jl. Cikutra No.204A, Bandung \\ adisukmana20@gmail.com $^{3}$
}

\begin{abstract}
Abstrak
Himpunan Mahasiwa Teknik Industri sendiri mempunyai staf dewan HMTI sebagai jabatan khusus yang bertanggung jawab besar dalam bergeraknya suatu organisasi yang dipimpin oleh Ketua Himpunan. Sistem penilaian kinerja anggota himpunan dilakukan pada setiap departemen untuk dievaluasi dalam menentukan para anggota yang memiliki kinerja baik. Alat ukur tersebut dapat ditentukan dengan menggunakan Key Performance Indicators (KPI). Untuk meningkatkan kinerja pengurus Himpunan tersebut hingga terpenuhi $100 \%$ maka dapat menggunakan strategi yaitu dengan memberikan reward pada kinerja mahasiswa. Cara lain untuk meningkatkan kinerja pengurus Himpunan tersebut yaitu melancarkan bagian administrasi dan persyaratan saat mengadakan acara.
\end{abstract}

Kata kunci:

Organisasi, Key Performance Indicators, Penilaian Kinerja

\begin{abstract}
The Industrial Engineering Student Association itself has the staff of the HMTI board as a special position who is responsible for the organization of the organization led by the Chairperson of the Association. The performance appraisal system of the members of the association is carried out in each department to be evaluated in determining the members who have good performance. The measuring instrument can be determined by using Key Performance Indicators (KPI). To improve the performance of the management of the Association
\end{abstract}

until it is fulfilled $100 \%$, it can use a strategy that is by giving rewards to student performance. Another way to improve the performance of the organizers of the Association is to smoothen administration and requirements when holding events.

Keywords:

Organization, Key Performance Indicators, Performance Appraisal

\section{Pendahuluan}

Organisasi pada dasarnya digunakan sebagai tempat atau wadah bagi mahasiswa dalam mengekspresikan aspirasi. Agar tercapainya tujuan didirikan organisasi tersebut maka dibutlah struktur organisasi supaya organisasi berjalan dengan baik. Di salah satu kampus Universitas Widyatama yaitu Himpunan Mahasiswa Teknik Industri (HMTI) terbagi dalam beberapa bagian departemen yang terdiri dari Departemen Pendidikan dan Organisasi, Departemen Sosial, Departemen Minat dan Bakat, Departemen Informasi dan Komunikasi, serta Departemen Kewirausahaan. Himpunan Mahasiwa Teknik Industri sendiri mempunyai staf dewan HMTI sebagai jabatan khusus yang bertanggung jawab besar dalam bergeraknya suatu organisasi yang dipimpin oleh Ketua Himpunan.

Sistem penilaian kinerja anggota himpunan dilakukan pada setiap departemen untuk dievaluasi dalam menentukan para anggota yang memiliki kinerja baik. Sistem penilaian anggota tersebut membutuhkan sistem penilaian kinerja yang lebih jelas maka diperlukan juga sebuah alat ukur (indikator). Himpunan Mahasiswa Teknik Industri memiliki indikator keberhasilannya yaitu dalam ketepatan waktu acara yang telah direncanakan, 
program kerja yang terlaksanakan dan jumlah anggota. Kinerja himpunan dikatakan berhasil apabila tiga indikator keberhasilan itu tercapai semua. Alat ukur tersebut dapat ditentukan dengan menggunakan Key Performance Indicators (KPI). Key Performance Indicators $(K P I)$ hanya digunakan sebagai alat untuk mengukur dan mengevaluasi kualitas yang berdampak terhadap kelangsungan organisasi. Penelitian ini menganggap suatu kasus yaitu melakukan penilaian anggota himpunan pada suatu organisasi berdasarkan metode Key Performance Indicators (KPI).

\section{KAJIAN LITERATUR}

Key Performance Indicator (KPI) merupakan alat bantu atau instrument manajemen agar suatu kegiatan atau proses dapat diikuti, dikendalikan (bila menyimpang, dapat dikenali untuk dikoreksi), dan dipastikan untuk mewujudkan kinerja yang dikehendaki. Salah satu cara agar mencapai indikator yang baik dalam penilaian kinerja karyawan dengan menggunakan metode KPI. KPI membandingkan apa yang telah dibuat dengan apa yang telah ditetapkan.

Implementasi yang berhasil akan tergantung pada pelaksanaan strategi pemeliharaan yang baik sesuai dengan apa yang telah ditetapkan (Ramadian, 2012). Key Performance Indicator $(K P I)$ atau Indikator Kinerja Utama adalah serangkaian indikator kunci yang bersifat terukur dan memberikan informasi sejauh mana sasaran strategis yang dibebankan kepada suatu organisasi sudah berhasil dicapai. Unsur-unsur yang terdapat dalam KPI terdiri atas tujuan strategis, indikator kunci yang relevan dengan sasaran strategis tersebut, sasaran yang menjadi tolak ukur dan kerangka waktu atau periode berlakunya KPI tersebut (Soemohadiwidjojo, 2015). KPI harus dipilih secara cermat untuk mencerminkan indikator kinerja yang penting bagi organisasi sesuai dengan strategi organisasi dan faktor kunci kesuksesan organisasi.

Penetapan KPI dan sasaran yang akan dicapai tidak dapat dilakukan secara asal-asalan, tetapi harus dipilih dan ditentukan menggunakan metode yang tepat dan sistematis. Memilih KPI dan menetapkan sasaran KPI secara tepat akan dapat mengarahkan organisasi pada identifikasi potensi perbaikan atau peningkatan kinerja sehingga KPI sering sekali diasosiasikan dengan inisiatif yang terkait peningkatan kinerja (Soemohadiwidjojo, 2015). Sebagai salah satu perangkat utama manajemen organisasi, tujuan utama dari penetapan $K P I$ tersebut adalah (Soemohadiwidjojo, 2015):

1. Untuk menghubungkan antara visi-misi-tata nilai, strategi organisasi, dan sasaran kinerja organisasi dengan aktifitas organisasi untuk mencapai sasaran kinerja yang diinginkan.

2. Untuk mengukujr tren kinerja organisasi dan/atau divisi apakah terdapat kenaikan atau terjadi penurunan yang signifikan.

3. Untuk membandingkan kinerja organisasi terkini dengan kinerja historis organisasi, atau membandingkan dengan kinerja organisasi lainnya sehingga organisasi medapatkan gambaran mengenai keunggulan atau kelemahan organisasi dibandingkan pesaing, serta mengetahui peluang-peluang untuk menciptakan nilai tambah.

4. KPI organisasi digunakan sebagai dasar penetapan KPI atau sasaran kerja divisi dan individu.

5. Hasil pencapaian KPI menjadi dasar untuk memberikan penghargaan dan konsekuensi sehingga KPI juga bermanfaat untuk mendorong motivasi bekerja dan perilaku yang baik dari karyawan.

\section{ANalisis dan Pembahasan}

Penelitian ini dilakukan di HIMA Prodi Teknik Industri Universitas Widyatama Bandung. Metode yang digunakan dalam penelitian ini adalah Key Performance Indicators $(K P I)$ 


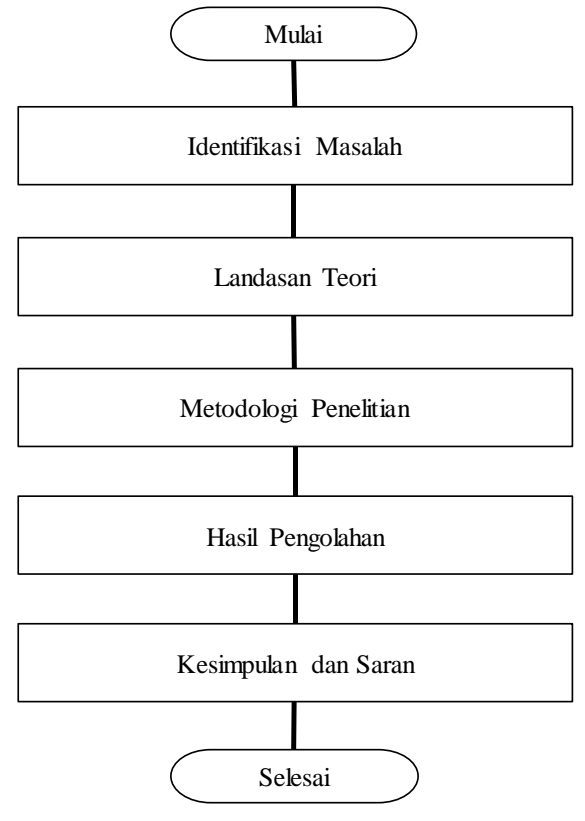

Gambar 1 Flowchart Penelitian

KPI menjelaskan apa yang hasrus dilakukan untuk meningkatkan kinerja secara dramatis. Parameter dalam KPI ditentukan dari pembobotan PI dimana hasilnya diperoleh berdasarkan objective, strategi, proses, dan kapabilitas data mengenai $K P I$.

Tabel 1 Hasil Kinerja Masa Bakti Periode 20162017

\begin{tabular}{|c|c|c|c|c|c|c|}
\hline $\mathrm{N}_{0}$ & \multicolumn{2}{|c|}{ Sukses Faktor } & Sasaran & Realita & Pencapaian & Keterangan \\
\hline \multirow{4}{*}{1} & \multirow{4}{*}{ Ketepatan Waktu Acara } & PPTI & 10-Sep-16 & 10-Sep-16 & 0 & Tepat Waktu \\
\hline & & RAMTI & 12-Nov-16 & 26-Nov-16 & 14 & Terlambat \\
\hline & & IECUP & 11-Feb-17 & 11-Feb-17 & 0 & Tepat Waktu \\
\hline & & BAKSOS & 25-Mar-17 & 11-Apr-17 & 17 & Terlambat \\
\hline 2 & Program Kerja Terlaksana & . & 4 & 4 & $100 \%$ & Tercapai \\
\hline 3 & Jumlah Anggota & $80 \%$ dari jumlah angkatan & 48 & 20 & $42 \%$ & Tidak Tercapai \\
\hline
\end{tabular}

Tabel 2 Hasil Kinerja Masa Bakti Periode 20172018

\begin{tabular}{|c|c|c|c|c|c|c|}
\hline No & \multicolumn{2}{|c|}{ Sukses Faktor } & Sasaran & Realita & Pencapaian & Keterangan \\
\hline \multirow{4}{*}{1} & \multirow{3}{*}{ Ketepatan Waktu Acara } & PPTI & 16-Sep-17 & 23-Sep-17 & 7 & Terlambat \\
\cline { 3 - 7 } & & RAMTI & $14-0 c t-17$ & $11-$ Nov-17 & 28 & Terlambat \\
\cline { 3 - 7 } & & IECUP & $09-D e c-17$ & $20-$-an-18 & 42 & Terlambat \\
\cline { 3 - 7 } & & BAKSOS & $10-$-Feb-18 & $14-$ Apr-18 & 63 & Terlambat \\
\hline 2 & Program Kerja Terlaksana & - & 4 & 4 & $100 \%$ & Tercapai \\
\hline 3 & Jumlah Angogta & $80 \%$ darijumlah angkatan & 60 & 48 & $80 \%$ & Tercapai \\
\hline
\end{tabular}

Tabel 3 Hasil Kinerja Masa Bakti Periode 20182019

\begin{tabular}{|c|c|c|c|c|c|c|}
\hline No & \multicolumn{2}{|c|}{ Sukses Fakkor } & Sasaran & Realita & Pencapaian & Keterangan \\
\hline \multirow{3}{*}{1} & \multirow{3}{*}{ Ketepatan Waktu Acara } & PPTI & 08-Sep-18 & 22-Sep-18 & 14 & Terlambat \\
\cline { 3 - 7 } & & RAMTI & 20-0ct-18 & $17-$ Nov-18 & 28 & Terlambat \\
\cline { 3 - 7 } & & ECUP & $15-$-Dec-18 & $19-J a n-19$ & 35 & Terlambat \\
\cline { 3 - 7 } & & BAKS0S & 23-Feb-19 & $23-$-Mar-19 & 28 & Terlambat \\
\hline 2 & Program Kerja Terlaksana & - & 4 & 4 & $100 \%$ & Tercapai \\
\hline 3 & Jumlah Anggota & 80\% dari jumlah angkatan & 50 & 25 & $50 \%$ & Tidak Tercapai \\
\hline
\end{tabular}

\section{KESIMPULAN DAN SARAN}

Setelah dilakukan pengolahan data menggunakan metode Key Perfomance Indicators $(K P I)$, maka dapat di terapkan pengukuran kinerja pada Himpunan Mahasiswa Teknik Industri Widyatama dari masa bakti tahun 2016-2017 sampai masa bakti 2018-2019 yaitu sebagai berikut:

Tabel 4 Persentase Hasil Ketepatan Waktu Acara

\begin{tabular}{|c|c|c|c|c|}
\hline No & Masa Bakti & Ketepatan Waktu Acara & Program Kerja & Jumlah Anggota \\
\hline 1 & $2016-2017$ & $92 \%$ & $100 \%$ & $42 \%$ \\
\hline 2 & $2017-2018$ & $65 \%$ & $100 \%$ & $80 \%$ \\
\hline 3 & $2018-2019$ & $74 \%$ & $100 \%$ & $50 \%$ \\
\hline
\end{tabular}

Berdasarkan Tabel 5.1 maka dapat diketahui bahwa pada masa bakti 2016-2017 memperoleh hasil rata-rata sebesar $92 \%$ yang berarti periode tersebut rata-rata telah menepati acara sesuai dengan waktu yang telah ditetapkan. Namun, dalam hal jumlah anggota masa bakti 2016-2017 memiliki jumlah anggota yang tidak memenuhi target. Dibandingkan dengan hasil rata-rata dua masa bakti lainnya yaitu masa bakti 2017-2018 dan 2018-2019, masa bakti 2016-2017 memiliki persentase tertinggi dalam hal ini berarti Key Performance Indicators (KPI) tercapai. Untuk meningkatkan kinerja pengurus Himpunan tersebut hingga terpenuhi $100 \%$ maka dapat menggunakan strategi yaitu dengan memberikan reward pada kinerja mahasiswa. Cara lain untuk meningkatkan kinerja pengurus Himpunan tersebut yaitu melancarkan bagian administrasi dan persyaratan saat mengadakan acara.

Saran yang dapat diajukan dalam penelitian kepada Himpunan Mahasiswa Teknik Industri Universitas Widyatama adalah sebagai berikut: 
1. Untuk meningkatkan kinerja karyawan di Himpunan Mahasiswa Teknik Industri Universitas Widyatama, Himpunan tersebut harus melakukan perbaikan berkelanjutan untuk mencapai tingkat kinerja yang maksimal.

2. Mahasiswa merupakan suatu aset yang sangat berharga bagi Himpunan, dengan memperhatikan keinginan mereka, dan memberikan pelatihan-pelatihan maka suatu Organisasi Himpunan di kampus akan jauh lebih baik lagi.

\section{REFERENSI}

Lubis, Kusumanto. Penilaian Kinerja Karyawan Menggunakan Metode Key Performance Indicators (KPI). Jurnal Sains, Teknologi dan Industri, Vol. 15, No. 2, Juni 2018, pp.37 45

Putri, Nilda Tri., Ramadian, Demi., Kamil, Insannul. “ Perancangan Standar Penilaian Kinerja Pemeliharan Lampu Jalan Berdasarkan Key Performance Indicators (KPI'S) (Studi Kasus Kota Padang)". Jurnal Optimasi Sistem Industri, Vol. 11 No. 2, Oktober 2012:225234. Padang. 2012

Soemohadiwidjojo, Arini T. "Panduan Praktis Menyusun Key Performance Indicator (KPI)". Cetakan I. Jakarta: Raih Asa Sukses. 2015

Tomigolung, F., Tarore, H., Sumajouw, Matrhin D. J. "Analisis Kinerja Konsultan Pengawas pada Proyek Jalan dan Jembatan di Sulawesi Utara". Jurnal Ilmiah Media Engineering Vol. 3, No. 2, ISSN: 2087-9334 (79-83). Manado. 2013

Wala, M., Mandagi, Robert J.M., Sompie, Bonny F. "Penilaian Kinerja Konsultan Perencana Bangunan dengan Metode Analytic Hierarchy Process (Studi pada Perencana Bangunan di manado)”. Jurnal Ilmiah Media Engineering Vol. 3, No. 2, ISSN: 2087-9334 (99-108). Manado. 2013 